\title{
A Multi-Group Analysis of Salient Determinants of E-government Implementation Success in Developing Countries. A Study of Uganda and Tanzania
}

\author{
Sumaya M. Kagoya \\ Department of Applied Computing and Information Technology \\ Makerere University Business School, Uganda \\ Email: thumakago@gmail.com/skagoya@mubs.ac.ug
}

Gerald Zachary Paga Tinali

University of Dar es Salaam Business School, Tanzania

Email: geraldpaga@yahoo.com

Jamie Caine

Department of Applied Computing, Sheffield Hallam University, England

Email: j.caine@ shu.ac.uk

\begin{abstract}
In-spite of the presence of all-encompassing synopsis of e-government implementation determinants in Most developed countries, a multi-group analysis of contextual salient determinants is missing in DCs. When it comes to implementation of e-government projects, most developing countries just copy already implemented projects from MDCs and paste without editing to suit their nations. This has resulted into massive failure of such e-projects partly due to failure to account the salient determinants of e-government implementation success which vary from one nation to another. This study bridges this knowledge gap by examining a multi-group analysis of contextual salient determinants of e-government implementation success in Uganda and Tanzania. Structured questionnaires were used to pucker quantitative data from the 72 employees and 64 employees from Ministries of finance and planning in Uganda and Tanzania respectively. PLS-SEM aided by SmartPLS 3 were used for analysis. Using UTAUT and empirical evidence, a model was proposed. Findings indicate insignificant results for information system attribute while all other constructs were significant. Findings for Tanzania indicated insignificant results for ICTI and ISA and positive significant results for TMS and UA. The Ugandan data set indicated insignificant results for ISA and TMS and positive significant results for ICTI and UA.
\end{abstract}

Keywords: Salient determinants, e-government implementation, developing cCountries, multi group analysis

https://dx.doi.org/10.4314/udslj.v16i2.9

\section{Introduction}

Of recent, most nations have embarked on e-government implementation since it has become a global measure of economic growth and development (Salehi, Abdollahbeigi \& Sajjady, 2021; Elbahnasawy, 2021; Malodia et al., 2021). Numerous authors have done a prodigious job of 
providing empirical foundations regarding e-government implementation success factors (Uyar et al., 2021; Glyptis et al., 2020). Globally, e-government implementation especially in most developed countries has brought supplementary benefits with success stories and these may entail; 24/7 e-service delivery, transparency and accountability, increased effectiveness and efficiency, cost reduction, increased e-participation, among others (Gong et al., 2020; Kagoya \& Mbamba, 2020). It should be recalled that e-government can be termed as the utilisation of ICTs by the government to deliver e-services to the end users who are the citizens, 24/7 without interruptions (Kagoya \& Gilbert, 2020). It may also mean the state functions which are in digital format (Malodia et al., 2021; Halsbenning et al., 2021).

E-government implementation in Tanzania and Uganda has been studied by prior authors to ascertain the level of adoption (Kagoya \& Mbamba, 2021, Khamis, 2020; Kagoya \&). For instance, Sichone and Mbamba (2021) noted that there was need to identify the key factors impacting the satisfaction of users and e-service quality which necessitated the development of a framework for e-government implementation success. Similarly, Anwer et al. (2016) echoed that in Tanzania, the user satisfaction perception about e-government services is not definite because the varying observational views given by prior authors. Magayane et al. (2016) portrayed that Tanzania is at digital presence and interaction stage in terms of e-government implementation, but there is absence of e-readiness by majority citizens (Kagoya \& Gilbert, 2020). On the other side, Uganda has websites for e-government service and information delivery to citizens. However, majority of the Ugandan citizens are not aware of such e-services, that are available due to failure of e-government developers to involve them in active participation of egovernment implementation (Kagoya \& Mbamba, 2021). These two developing nations were the appropriate choices for this the multigroup analysis due to the fact that, they face some similar ICT related hitches when it comes to e-government implementation aspects (Kagoya\& Mbamba, 2021).

This study has acknowledged the incredible work done by previous scholars have continued to propose and develop e-government frameworks (Malodia et al., 2021; Ahmad et al., 2021; Singh et al., 2020; Roblek et al., 2020; Dias, 2020), e-government readiness assessment tools (Alghamdi, Goodwin \& Rampersad, 2016; Assefa et al., 2021; Kagoya \& Gilbert, 2020; Haydari, 2020; Pal, Singh \& Dhaliwal, 2020). And other studies have suggested models for egovernment implementation (Elbahnasawy, 2021; Li \& Xue, 2021; Sharma et al., 2021; Li, 2021; Alkraiji, 2020). In spite of the great empirical literature provided by preceding authors in line with e-government, there is has not been a study addressing the a multigroup analysis of the key salient determinants for e-government implementation success in developing countries like Uganda and Tanzania.

Furthermore, the reviewed literature confirms that, majority of such studies were conducted mainly in most developed economies using qualitative research approach which makes their findings un generalizable to developing economies like Uganda and Tanzania (Kagoya \& Gilbert, 2020). Worse still, those which were implemented in developing nations, $70 \%$ failed since they were just copied from those most developed countries with different technological, social, economic, ecological, political and geographical settings (Kagoya \& Mbamba, 2021). Hinged on this background, the need to reduce this high failure rate egovernment projects in developing countries under study, motivates this study. This study specifically grouped salient determinants into four (user attributes, information system attributes,

A Multi-Group Analysis of Salient Determinants of E-government Implementation Success in Developing Countries. A Study of Uganda and Tanzania

Sumaya M. Kagoya, Gerald Zachary Paga Tinali \& Jamie Caine 
top management support and information and communication technology infrastructure attributes) to serve the contextual aspects of Uganda and Tanzania.

\section{Literature review}

\section{Theoretical background}

Prior studies emphasize the need for writing quantitative research supported by theoretical background to get rid of biasness, which may affect the actual field results (Kazdin, 2021; Schreurs \& Vandenbosch, 2021;). It is also imperative to note that theoretical background tend to align the objectives, methods plus research findings which makes the study more clear, linked and understandable (Chu et al., 2021; Zina, 2021).

\section{Unified Theory of Acceptance and Use of Technology (UTAUT)}

Preceding researchers about UTAUT theory as developed by Venkatesh et al. (2003) assert that it is regarded as a reflection on beliefs of an individual's internal schema (Venkatesh, Thong \& Xu, 2016; Joa \& Magsamen-Conrad, 2021; Eapen, 2021). UTAUT which modifies TAM model, comprises of eight competing technology acceptance models of Technology Acceptance Model (TAM), Theory of Reasoned Action (TRA), Theory of Planned Behaviour (TPB), motivation model, innovation diffusion theory, TAM/TPB combined PC utilization model, and social cognitive theory.

UTAUT theorizes that an individual's behavioural intention to use technology, is influenced by performance expectancy, effort expectancy, social influence, and facilitating conditions (Venkatesh, 2021; Arfi, Nasr, Khvatova \& Zaied, 2021). Given its importance in the field of e-government and information system research areas, voluminous researchers have utilized UTAUT in their studies (such as; Venkatesh, 2021; Qaid, Samikoni \& Fahmi, 2021; Kagoya \& Mbamba, 2021; Altalhi, 2021; Maznorbalia \& Awalluddin, 2021; Kagoya \& Mbamba, 2021; Raza et al., 2021; Abbad, 2021; Kagoya \& Mbamba, 2020; Almaiah \& Nasereddin, 2020; Kagoya \& Mkwizu, 2020). For instance, Almaiah and Nasereddin (2020) used UTAUT theory for examining factors affecting e-government services adoption among the citizens of Jordan, while Eapen (2021) used UTAUT theory of adoption for establishing the clinical support systems.

Additionally, UTAUT theory was applied by Venkatesh (2021) in the adoption and usage of Artificial tools, whereas Raza et al. (2021) applied UTAUT in Covid-19 pandemic for acceptance and social isolation via learning management system. Additionally, Kurfali et al. (2017) used UTAUT in the Turkish study on e-government adoption, while Kagoya and Mbamba (2021) used UTAUT to assess e-government implementation factors in Tanzania and their findings divulged that key attribute from individual users and support from key top managers, were paramount for successful implementation of e-government. Moreover, Maznorbalia and Awalluddin (2021) utilized UTAUT theory in analyzing the acceptance of egovernment system by end-users in Sintok, Malaysia. On the contrary, this study intends to apply UTAUT theory to ascertain the salient determinants of e-government implementation success in Uganda and Tanzania as part of the developing nations on the African continent. The reason for 
utilizing UTAUT in this study is to identify the contextual specific individual beliefs which influence the users' acceptance to use e-government systems in both Uganda and Tanzania. UTAUT is useful in this study as it lays a theoretical contribution by supporting the exogenous variables such as user attributes, where by individual end users are able to accept, adopt and use the technology with the support from top management. This support may be in terms of ICT infrastructure, information system support, ICT training, hardware and software; among others, in the context of Uganda and Tanzania.

This study differed from previous studies in that, it proposed an additional variable of user attributes to the UTAUT while others studies conceptualized it, as e-readiness, peer influence (AlAwadhi \& Moris, 2008; Al-rawahna, Chen, Hung, 2018). More so, this study is of the view that, peer pressure (one of the user attributes) may influence e-government implementation success which is supported by UTAUT through its indicator of social influence. Furthermore, using UTAUT together with a support of empirical evidence, a model with four exogenous latent variables and one endogenous latent variable was proposed. The model proposed the salient determinants of e-government implementations success namely user attributes (UA), Information System Attributes (ISA), top management support (TMS) and Information and Communication Technology Infrastructure attributes (ICTI).

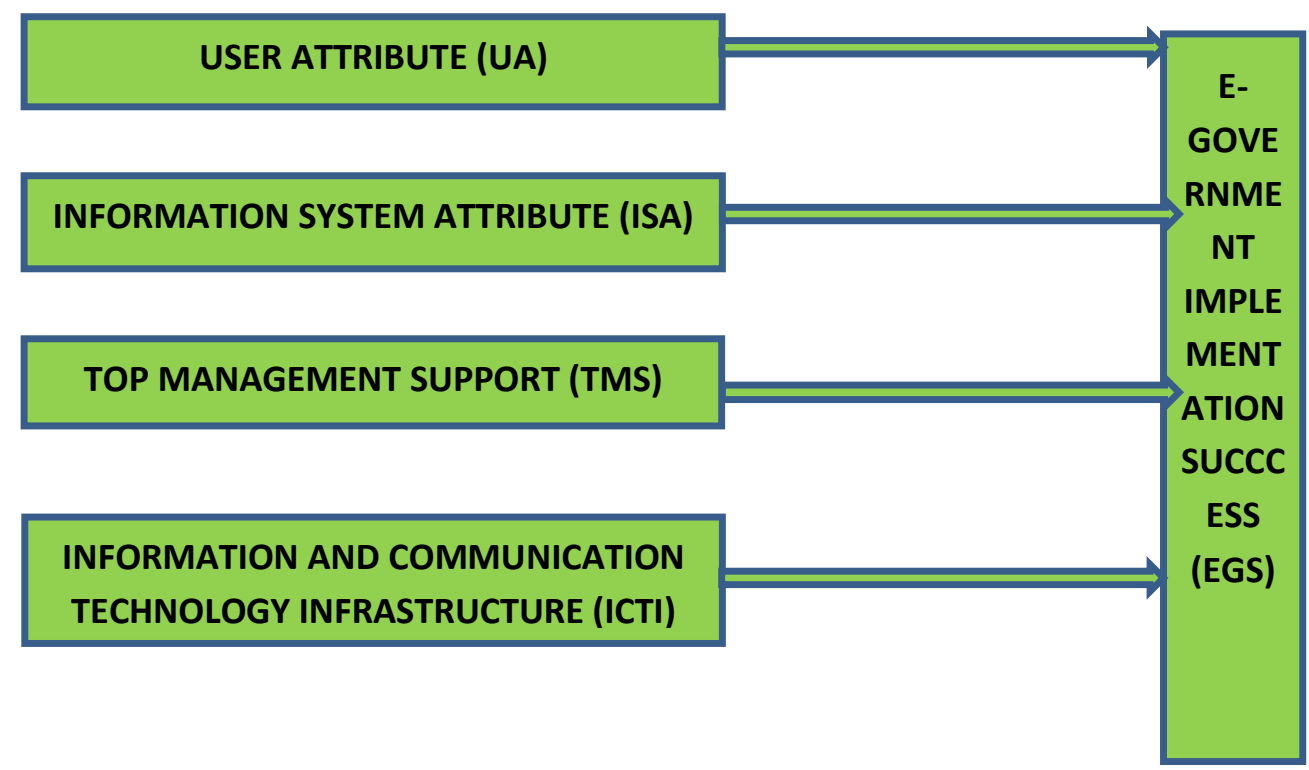

Figure 1: E-government implementation model for developing countries (Source: Literature review)

\section{Empirical literature review}

Gerger (2021) conducted a study to determine the critical factors to assess the usability of web 2.0 technologies for e-government transparency and effectiveness. Findings culminated into the formation of some critical success factors for e-government implementation and these were; transparent, human-cantered e-government applications, applicability, dynamic and social A Multi-Group Analysis of Salient Determinants of E-government Implementation Success in Developing Countries. A Study of Uganda and Tanzania 
aspects. Khan, Krishnan \& Dhir (2021) studied e-government and corruption via a systematic literature review of 63 articles. The study developed an integrated framework to guide the egovernment developers, government policy makers and future researchers on a clear understanding of e-government aspects.

Yera et al. (2015) conducted a study in Europe to examine the characterization of the adoption of e-government via ranking the measures of e-readiness. The findings of the ranking comparison revealed that E-government Use Index $\left(\mathrm{EGUI}^{+}\right)$correlated at $5 \%$ level of significance with the four indexes, hence contributing to the clarity regarding the key factors affecting e-government usage in Europe plus its various stages of adoption. Manoharan et al. (2021) established five superlative groups for city e-governments which entailed: content, usability, services, security and privacy, social and citizen engagement.

Correspondingly, the author identified three groups of developers of e-governance and opined that, it was only in the development curve central point, that possess fastest growing cities thus depicting a climber marvel in the world dispersion drifts of e-governance. Contrarywise, this current study asserts that, there is need for developing countries (such as, Uganda and Tanzania) to conduct a multigroup analysis to ascertain the specific contextual salient determinants of e-government implementation success and avoid copy and paste mechanism of successful e-projects from MDCs. This will eventually aid in reducing the massive failure of such e-projects in developing countries as suggested by Kagoya and Mbamba (2021).

Additionally, Amogoh (2016) conducted a study in Nigeria to ascertain the e-government diffusion determinants using questionnaires, with queries regarding the three models (TAM, DOI and UTAUT). Findings opined that, the two prominent factors of reliability of electricity supply and trust in government were not within the theoretical dimensions, perhaps due to contextual differences. Kagoya and Gilbert (2020) evaluated e-government readiness in the Ugandan Ministries of ICT and national guidance, Finance, planning and economic development and Ministry of works and transport. Using descriptive statistical analysis on the gathered quantitative data, the results envisaged the development of EGRAF (E-government readiness assessment framework) for Uganda to enhance the citizen awareness about e-government for easy adoption and user participation purposes, hence increased e-government readiness.

Kagoya and Mbamba (2021) conducted a study about e-government implementation in Uganda, using positivism philosophical research orientations and deductive quantitative approach, results depicted that top management support, acts as moderating exogenous variable in the relationship between e-government implementation and user participation attributes in the Ugandan context. In this study, top management support is a predictor in both Uganda and Tanzania and not a moderator, and the difference perhaps is due to the differences in the time lag and the respondents' views by the time of the study. This also implies that top management support can be used as both a predictor and a moderator in the Ugandan context, when it comes to e-government implementation success.

Prior authors in Yemen institute of higher learning developed a conceptual e-government theoretical model based on UTAUT plus ICT innovations for lecturers' adoption that give a theoretical contribution and strategies for upcoming researchers in the developing world in line with e-government adoption and implementation (Qaid, Samikoni \& Fahmi, 2021). Finally, Moon (2002) argue that, e-government implementation effectiveness and scope vary from nation to nation. The author asserted that some countries' e-government projects were developed based 
on their websites and the Internet aid users during interactivity and usability purposes. Equally, some nations' e-government maturity stages differ from one another depending on the varying factors, such as economic status, political, social, cultural, technological and environmental factors (Shareef et al., 2021; Kagoya \& Mbamba, 2021; Ingrams et al., 2020). Therefore, this research study suggests that, irrespective of the level of e-government development, a nation is at, e-government developers coupled with others key e-government stakeholders must consider the contextual salient determinants stipulated in the model, for successful e-government implementation. Some countries' e-government projects were developed based on their websites and the Internet that aid users during interactivity and usability purposes (Manoharan et al., 2021; Verkijika, \& De Wet, 2018).

\section{Methodology}

This study was carried out in the contexts of Uganda and Tanzania to examine the silent determinants of e-government implementation success in less developed countries (LDCS). A cross sectional design and structured questionnaires were used to pucker quantitative data from the 72 employees and 64 employees from ministry of finance in Uganda and ministry of finance and planning in Tanzania respectively. The study population included all e-government users (employees) in ministries for both Uganda and Tanzania.

To avoid the situation of some respondents being reluctant in responding to the questions presented to them, the study opted for non-probabilistic sampling procedure and the respondents were conveniently and purposively selected. Uganda and Tanzania were chosen as countries of survey due to convenience of the researchers in terms of time and financial resources. The choice of the aforesaid Ministries was that, their respondents were exercising government electronic operations (MO ICT report, 2018; United Republic of Tanzania, 2014) and also the selected ministries were good representatives of the rest of the ministries in both countries since they are managing $90 \%$ most of the ICT related national projects (Kagoya \& Mbamba, 2020). Thus, Kampala and Dar es Salaam cities in were included and prior information to these cities were obtained, to know the respondents who were using the systems for their inclusion in the study.

The survey tool covered questions related to the user participation (including their attributes, IS attributes as well as ICT infrastructure that can affect usage); top management support; and e-government implementation success. Knowing the criticality of ethical consideration as advocated by previous researchers (Williamson et al., 2021; Creswell et al., 2021; Vol et al., 2021), the study obtained consent from respondents and protected the interest of the respondent to safeguard the privacy and confidentiality issues which helped in reducing biasness hence acting as part of the common method bias (Kock, Berbekova \& Assaf, 2021; Buijs \& Jacobs, 2021). Also the study at the introduction part of the questionnaire, the respondents were assured on their anonymity and confiidentialty. This effort enabled respondents to be open on reponding to the questions addresed to them (Poerwandari, 2021).

The study used a PLS-MGA (Partial Least Squared - Multi-group Analysis for data analysis which was suitable for comparative analysis between two countries results in the scope. It worth noting that, PLS-MGA assesses the measurement characteristics of the latent constructs comprising of the MICOM procedure hence supplementing on the accuracy level of the findings (Ritchie et al., 2020; Dewi, Mohaidin \& Murshid, 2019). Additionally, it aids researchers to

A Multi-Group Analysis of Salient Determinants of E-government Implementation Success in Developing Countries. A Study of Uganda and Tanzania

Sumaya M. Kagoya, Gerald Zachary Paga Tinali \& Jamie Caine 
advance on the possibility of attaining vital and significant differences across group-specific results among numerous relationships that builds on PLS-SEM bootstrapping results (Hair et al., 2018; Sarstedt et al., 2018). More so, PLS MGA being an extension of the original Henseler's MGA non-parametric significant test (Olya et al., 2021; Sarstedt et al., 2011), enabled the researchers to unearth dissimilarities of sub elements/ subsamples from the total population.

The quantitative data obtained, was screened before performing the analysis and the screening involved checking for the accuracy of the data entered into a system, suspicious response patterns and missing data (Mücke et al., 2021; Chung et al., 2021). Data analysis involved descriptive, discriminant validity, convergent validity and composite reliability tests (Pontes et al., 2021; Hair et al., 2017). Variable items similar to the study problem were adapted from Fan and Yang (2015), which ensured more efficiency for validity and reliability (Rehman Khan \&, 2021; Low et al., 2021) and were able to answer research questions and meet the objectives (Saunders, 2021; Perucchetti et al., 2021).

\section{Results}

\section{Descriptive Statistics of the Sample}

Table 1 revealed that of the 136 respondents 64 (47\%) were from Tanzania and $72(53 \%)$ were from Tanzania, this indicates nearer equal representation of the respondents from both countries. Furthermore, based on gender majority of the respondents in both countries were male $87(64 \%)$ however, there was a significant number of female respondents $49(36 \%)$, an indication that both male and female respondents were considered in a significant number under this study.

Table 1: Demographic Information

\begin{tabular}{lllll}
\hline & & Gender & Female & Total \\
Country & Male & 37 & 64 \\
Tanzania & 37 & 22 & 72 \\
Uganda & 50 & 49 & 136 \\
Total & 87 & & 27 \\
\hline
\end{tabular}

\section{Assessment of Measurement Model}

Initially the model was validated for the whole sample and then was grouped into two groups that are a sample contains responses from Tanzania and Uganda. After running the PLS algorithms the model result reveal that all measures meet the required criteria as describe in the Table 2 below.

Table 2: Country Specific Results

\begin{tabular}{lllll}
\hline $\begin{array}{l}\text { Latent } \\
\text { Variables }\end{array}$ & & Tanzania & Uganda & All \\
\hline EGS & CR & 0.959 & 0.910 & 0.934 \\
& AVE & 0.825 & 0.673 & 0.739 \\
ICTI & CR & 0.868 & 0.706 & 0.804 \\
& AVE & 0.623 & 0.385 & 0.507 \\
\hline
\end{tabular}




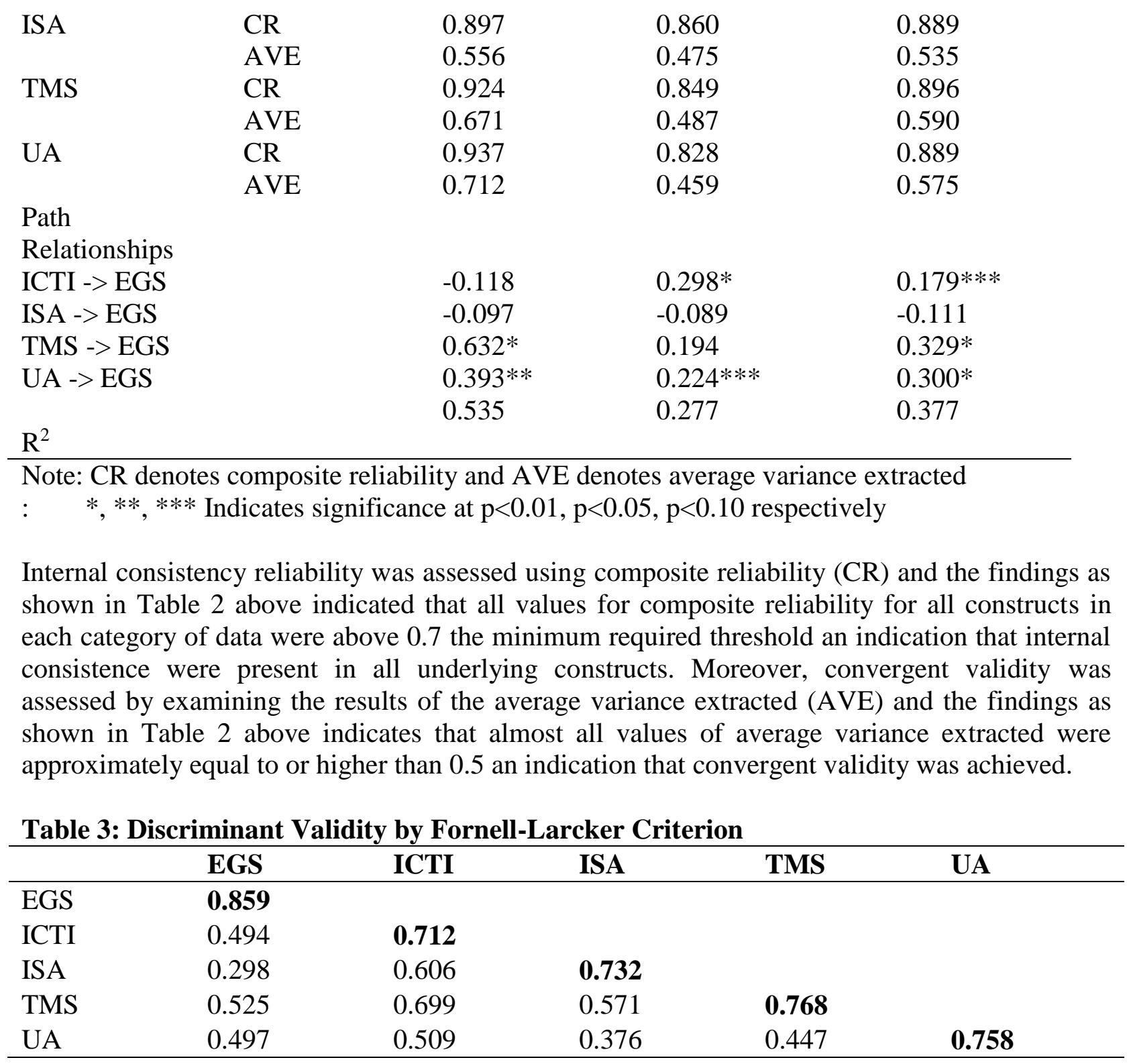

Additionally, to assess the discriminant validity the study used the Fornell-Larcker criteria whereby the square roots of the average variance extracted were compared to the correlation of all other constructs. The findings as in Table 3 indicates that all the correlations were smaller relative to the square roots of the average variance extracted along the diagonal an indication that discriminant validity was satisfied.

\section{Structural Model Results}

As indicated in the Table 1 above, the findings for the complete data set indicates insignificance results for information system attribute while all other constructs were significant (ICTI: $\mathrm{p}<0.1$, TMS: $\mathrm{p}<0.01$, UA: $\mathrm{p}<0.01)$. Findings for Tanzania data indicated insignificant results for both ICTI and ISA and positive significant results for TMS and UA (TMS: $\mathrm{p}<0.01$, UA: $\mathrm{p}<0.05$ ). The A Multi-Group Analysis of Salient Determinants of E-government Implementation Success in Developing Countries. A Study of Uganda and Tanzania 
$\overline{\text { Ugandan data set indicated insignificant results for ISA and TMS and positive significant results }}$ for ICTI and UA (ICTI: $\mathrm{p}<0.01$, UA: $\mathrm{p}<0.1$ ).

\section{Testing for Measurement Model Invariance}

Before comparing group parameter estimates using multgroup analysis it is required first to check for measurement model invariance (Hair, Sarstedt, Ringle, \& Gudergan, 2018). The establishment of measurement model invariance provides an assurance that in the model group differences exist not because of distinctive contents (Kuppelwieser, 2021; Goncalves, 2013). Therefore, to test for measurement model invariance, this study used the measurement invariance of composite models (MICOM) following the three steps as described in the following sections (Balzarotti, 2021). Basically, the three steps aimed at checking the existence of configural invariance, compositional invariance and equality of composite mean values and variances.

MICOM $1^{\text {st }}$ Step involves checking for configural invariance. To ensure that the configural invariance for this study, first the study ensured the study measures what is supposed to measure by sharing the measurement items with practitioners and academicians who were experts in the concept and their feedback were incorporated before final data collection. Moreover, for both groups, treatment of missing values and outliers, coding was the same across the two groups. Furthermore, the algorithm settings in the software were the same for all two groups. Consequently, all these ensured the establishment of configural invariance as recommended by preceding authors (Ngah et al., 2021; Ghazali, Mutum \& Javadi, 2021; Keung et al., 2021).

Table 4: MICOM $2^{\text {nd }}$ Step Results

\begin{tabular}{llllll}
\hline Composite & $\begin{array}{l}\text { Correlation } \\
\text { (c) }\end{array}$ & $\begin{array}{l}\text { Correlation } \\
\text { Permutation } \\
\text { Mean }\end{array}$ & $\begin{array}{l}5 \% \text { Quantile of } \\
\text { the Empirical } \\
\text { Distribution of cu }\end{array}$ & $\begin{array}{l}\text { Permutation } \\
\text { p-Values }\end{array}$ & $\begin{array}{l}\text { Compositional } \\
\text { Invariance } \\
\text { Established }\end{array}$ \\
\hline EGS & 0.998 & 0.999 & 0.996 & 0.141 & Yes \\
ICTI & 0.955 & 0.969 & 0.919 & 0.222 & Yes \\
ISA & 0.962 & 0.952 & 0.847 & 0.330 & Yes \\
TMS & 0.991 & 0.989 & 0.965 & 0.425 & Yes \\
UA & 0.987 & 0.986 & 0.957 & 0.299 & Yes \\
\hline
\end{tabular}

After being assured on the existence of configural invariance as explained in the MICOM first step, the next step was to assess the compositional invariance. This was done by running a permutation test with a minimum number of 1000 permutations. For compositional invariance assessment the aim was not to reject the null hypothesis at $5 \%$ level of significant, that the correlation between the composite scores of groups one and two (c) is equal to one. Findings as on Table 4 above through comparing the correlation (c) with the 5\% Quantile indicated the Quantile to be smaller than the correlation in each composite thus signify the establishment of compositional invariance.

These results were also backed up by permutation p-values results whereby for all composite the values of $\mathrm{p}$ were greater than 0.5 indicating the failure to reject the null hypothesis at $5 \%$ level of significant. Therefore, the establishment of compositional invariance indicates the 
existence of partial measurement invariance, this provides justification for our study to compare the path coefficients by means of multgroup analysis (MGA).

Table 5: MICOM 3rd Step (a) Results

\begin{tabular}{|c|c|c|c|c|c|}
\hline Composite & $\begin{array}{l}\text { Differences of the } \\
\text { Composite Mean } \\
\text { Value }(=0) \\
\text { (Tanzania-Uganda) }\end{array}$ & $\begin{array}{l}95 \% \\
\text { Interval }\end{array}$ & p-Values & $\begin{array}{l}\text { Equal } \\
\text { Values? }\end{array}$ & Mean \\
\hline EGS & 0.067 & {$[-0.320 ; 0.346]$} & 0.711 & Yes & \\
\hline ICTI & -0.055 & {$[-0.318 ; 0.323]$} & 0.772 & Yes & \\
\hline ISA & -0.381 & {$[-0.313 ; 0.342]$} & 0.025 & No & \\
\hline TMS & 0.148 & {$[-0.333 ; 0.348]$} & 0.390 & Yes & \\
\hline UA & 0.094 & {$[-0.350 ; 0.335]$} & 0.590 & Yes & \\
\hline
\end{tabular}

Table 6: MICOM 3rd Step (b) Results

\begin{tabular}{|c|c|c|c|c|}
\hline Composite & $\begin{array}{l}\text { Logarithms of } \text { the } \\
\text { Composite's Variance Ratio } \\
(=0) \\
\text { (Tanzania - Uganda) }\end{array}$ & $95 \%$ confidence Interval & p-Values & Equal Variance? \\
\hline EGS & 0.203 & {$[-0.577 ; 0.583]$} & 0.529 & Yes \\
\hline ICTI & 0.462 & {$[-0.517 ; 0.480]$} & 0.069 & Yes \\
\hline ISA & -0.094 & {$[-0.497 ; 0.496]$} & 0.758 & Yes \\
\hline TMS & 0.684 & {$[-0.633 ; 0.570]$} & 0.033 & No \\
\hline UA & 0.664 & {$[-1.084 ; 1.082]$} & 0.270 & Yes \\
\hline
\end{tabular}

Given the fact that, the results as discussed above indicated the existence of compositional invariance, this study proceed with the final step for testing the equality of composite mean values and variances of the data from Tanzania and Uganda. Based on the findings in the Table 6, with the exception of information system attribute (ISA), all other confidence intervals included the original difference in mean value. This is an indication that there is no significance difference in the mean values of latent variables across the two groups.

These results are further supported by the results for $\mathrm{p}$ values. For composite variance, with the exception of top management support (TMS), all other confidence intervals include logarithm of the composite variance. Also, with the exception of top management support (TMS), all $\mathrm{p}$ values were greater than 0.05 .

\section{Multi-group Analysis (MGA)}

A Multi-Group Analysis of Salient Determinants of E-government Implementation Success in Developing Countries. A Study of Uganda and Tanzania

Sumaya M. Kagoya, Gerald Zachary Paga Tinali \& Jamie Caine 
As stated earlier, the existence of compositional invariance indicates the existence of partial measurement invariance, thus providing justification and motivation for this study, that is to compare the path coefficients by means of multigroup analysis (Assaker et al., 2021; Jamal et al., 2021). Furthermore, the multigroup analysis used in this study, aimed at testing the null hypothesis if the path coefficients between two groups (Tanzania and Uganda) are not significantly different, while the alternative hypothesis was to test whether the path coefficients were different (Ghazali, Mutum \& Javadi, 2021; Toyoda et al., 2021).

To explore this, the current researchers first focused on the results of permutation test and then analysed the group specific effects by running a multi-group analysis (MGA) approach on the quantitative data. The details are as described in the following results and discussions of the data obtained.

Table 7: Permutation Test Results

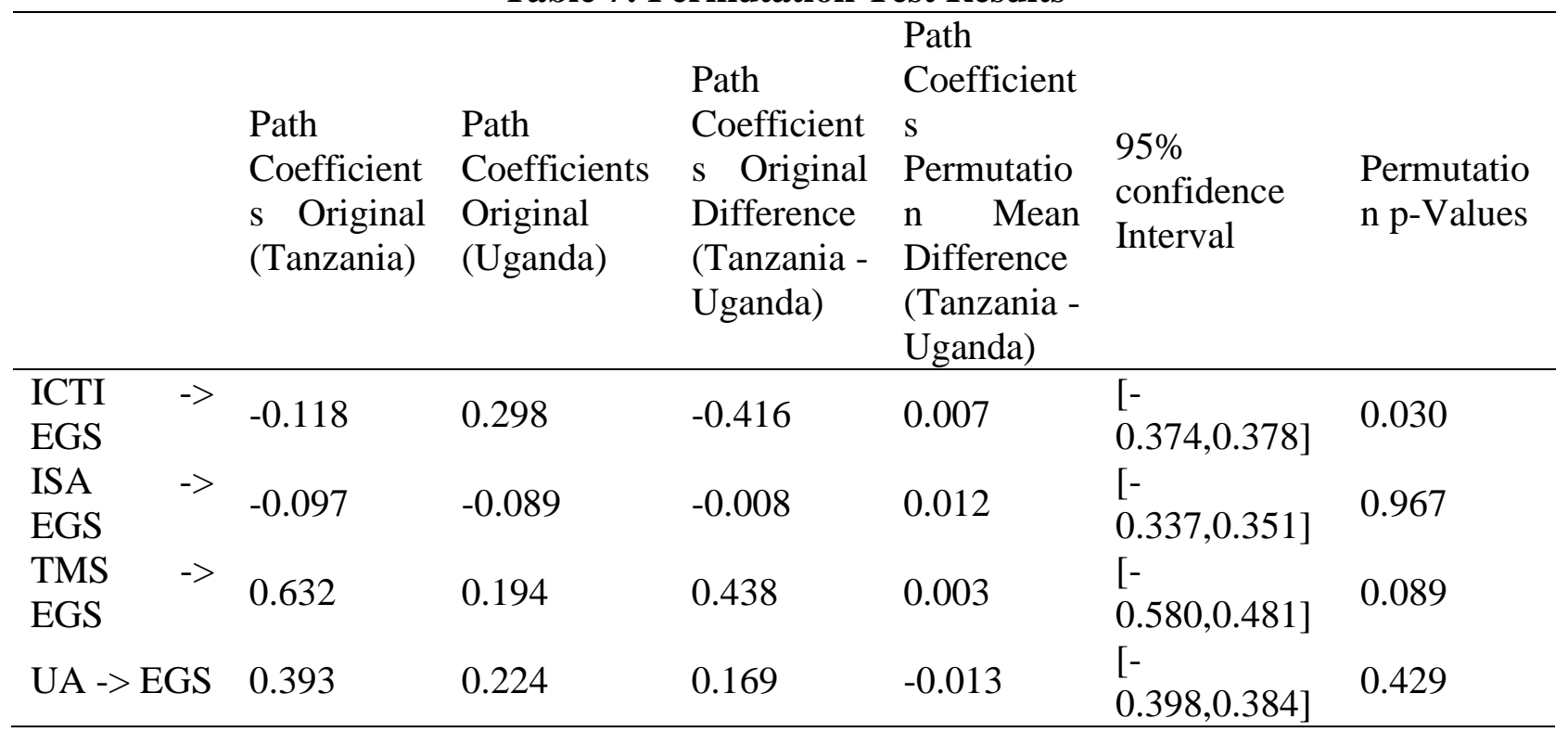

Permutation test results portray that, two out of four structural model relationships do not differ between the respondents from Tanzania and Uganda. The findings designate the relationship between information and communication technology infrastructure (ICTI) attributes and e-government implementation success (EGS) differs significantly, that is the effect between ICTI and EGS is significant $(\mathrm{p}<0.05)$ different between the respondents from Tanzania $\left(\beta_{\text {Tanzania }}\right.$ $=-0.118$ ) compared to those from Uganda ( $\left.\beta_{\text {Uganda }}=0.298\right)$. Moreover, findings show that, the relationship between top management support (TMS) and e-government implementation success (EGS) differs significantly between the two groups. That is to say, the effect between TMS and EGS is significantly $(\mathrm{p}<0.10)$ different between the respondents from Tanzania $\left(\beta_{\text {Tanzania }}=0.632\right)$ compared to those from Uganda $\left(\beta_{\text {Uganda }}=0.194\right)$. 
In order to obtain a clear difference between these two groups, this study further conducted a mult group analysis (MGA) in SmartPLS 3 and the results for PLS -MGA, Parametric Test and Welch-Satterthwaite $t$ Test are as displayed in the Table 8 below and discussed thereafter.

Table 8: PLS -MGA, Parametric Test and Welch-Satterthwaite t Test Results

\begin{tabular}{llll}
\hline Path Coefficients & $\begin{array}{l}\text { Path Coefficients-diff } \\
\text { (Tanzania - Uganda) }\end{array}$ & $\begin{array}{l}\text { t-Value } \\
\text { (Tanzania vs. Uganda) }\end{array}$ & $\begin{array}{l}\text { p-Value } \\
\text { (Tanzania vs Uganda) }\end{array}$ \\
\hline PLS - MGA & & & 0.976 \\
ICTI -> EGS & 0.416 & & 0.530 \\
ISA -> EGS & 0.008 & & 0.047 \\
TMS -> EGS & 0.438 & & 0.212 \\
UA -> EGS & 0.169 & & \\
& & & \\
Parametric Test & & 2.000 & 0.048 \\
ICTI -> EGS & 0.416 & 0.033 & 0.974 \\
ISA -> EGS & 0.008 & 1.730 & 0.086 \\
TMS -> EGS & 0.438 & 0.831 & 0.407 \\
UA -> EGS & 0.169 & & \\
Welch-Satterthwaite & Test & 1.950 & 0.056 \\
ICTI -> EGS & 0.416 & 0.032 & 0.974 \\
ISA -> EGS & 0.008 & 1.702 & 0.094 \\
TMS -> EGS & 0.438 & 0.817 & 0.417 \\
UA -> EGS & 0.169 & & \\
\hline
\end{tabular}

A PLS MGA results as it represents a one tailed test indicates the path coefficient based on respondent from Tanzania is significantly $(\mathrm{p}<0.05)$ larger than the path coefficient based in Uganda for top management support (TMS) and e-government implementation success (EGS) relationships. Through taking the $1-\mathrm{p}$ value however the result indicates the path coefficient based on respondents from Uganda is significantly $(\mathrm{p}<0.05)$ larger than the path coefficient in in Tanzania for the information and communication technology infrastructure (ICTI) attributes and e-government implementation success (EGS) relationships. Furthermore, parametric test and Welch-Satterthwaite $t$ test results were also checked and seem to provide similar conclusion as PLS-MGA results (Pontes et al., 2021).

Table 9: Comparison of PLS Multi-group Results across Methods

\begin{tabular}{lllll}
\hline Path Coefficient & $\begin{array}{l}\text { Permutation } \\
\text { Test }\end{array}$ & PLS -MGA & $\begin{array}{l}\text { Parametric } \\
\text { Test }\end{array}$ & $\begin{array}{l}\text { Welch-Satterthwaite } \\
\text { t Test }\end{array}$ \\
\hline ICTI -> EGS & $* *$ & $* *$ & $* *$ & $* * *$ \\
ISA -> EGS & & & & $* * *$ \\
TMS -> EGS & $* * *$ & $* *$ & & $* *$ \\
UA -> EGS & & & & \\
\hline
\end{tabular}

A Multi-Group Analysis of Salient Determinants of E-government Implementation Success in Developing Countries. A Study of Uganda and Tanzania

Sumaya M. Kagoya, Gerald Zachary Paga Tinali \& Jamie Caine 
Notes: $*, * *, * * *$ Indicates significance difference $(\mathrm{p}<0.01, \mathrm{p}<0.05, \mathrm{p}<0.10$ respectively) of path coefficients across groups

By comparing on the results from different methods as indicated in Table 9, all the methods indicated path coefficients for ICTI to EGS and TMS to EGS were significantly different between the two data groups with the rest of path coefficient being similar across the groups. This multi-method comparison provides an additional confidence on the results obtained for this study (Walker et al., 2021; Cuhadar et al., 2021).

\section{Discussion of the Results}

This study examined a multi-group analysis to examine the silent determinants of egovernment implementation success in developing countries with special reference to Uganda and Tanzania. The results for the combined data set showed that information system attribute was negatively and insignificantly related to e-government implementations success. Nevertheless, ICTI, TMS and UA were positively and significantly related to e-government implementations success. The findings are in support of UTAUT in a context of including the UA as a critical factor towards e-government implementations success. This study supports previous studies who also found ICTI, TMS or UA significantly positively related to egovernment implementations success (Olugbara \& Joseph, 2018; Kaaya, 2012;).

Furthermore, results for Tanzania data were insignificant results for both ICTI and ISA and positive significant results for TMS and UA. The significant results of TMS and UA in Tanzania data are in line with previous literature which supported the importance of top management support and user attributes towards successful information technology applications in organizations (Kagoya \& Mbamba, 2021; Olugbara \& Joseph, 2018; Kaaya, 2012; Dong et al., 2009; Ragu-Nathan et al., 2004). The Ugandan data set indicated insignificant results for ISA and TMS, and positive significant results for ICTI and UA. The significance results of ICTI and UA in Uganda data are in support of UTAUT together with other previous studies which used some of the proposed variables for e-government implementation success (Kagoya \& Mbamba, 2021; Kaaya, 2012; Kagoya \& Mbamba 2020; Olugbara \& Joseph, 2018).

Nevertheless, further analysis using a multgroup analysis revealed that the path confidents for for ICTI to EGS and TMS to EGS were significantly different between the two data groups with the rest of path coefficient being similar across the groups. The difference in other key salient determinants may be due to the differences in the leadership style, socialcultural related issues, plus technological levels and different economic muscles.

\section{Study Implications, Limitation and Future Research}

Since the current study findings envisaged that the path coefficients for ICTI to EGS and TMS to EGS were significantly different between the two data groups, a lesson can be drawn especially to the e-government implementers and practitioners to consider the issue of 
geographical differences rather than coping and pasting e-government projects and strategies from most developed countries. This study argues policy makers and all other relevant stakeholders in e-government implementation in Uganda to formulate policies that will support user participation attributes and ICT infrastructure attributes while those of Tanzania should embark on policies that involve users' participation attributes and top management support, as the key salient determinants for successful e-government implementation. Additionally, the study provides a significant methodological and empirical contribution to studies involving multigroup analysis using partial least square structural equation models, given the fact that it was the first of its kind in the developing countries specifically in Uganda and Tanzania.

Several limitations of this study need to be noted and taken into considerations in future studies. The study opted for cross-sectional design, but given the advantages the longitudinal studies possess over cross sectional studies further studies should concentrate on longitudinal research design. The study concentrated only on the direct relationships between the predictor variables (user attributes (UA), Information System Attributes (ISA), top management support (TMS) and Information and Communication Technology Infrastructure attributes (ICTI) and the predicted variable, we recommend future studies to concentrate on mediators and moderator variables hoping for more qualities compared to the study at hand.

\section{Conclusion}

This study used a multi-group analysis to determine the salient determinants of egovernment implementation success in Uganda and Tanzania. Using cross sectional design, quantitative data was gathered from the two countries for comparative purposes. Findings revealed that, in Uganda, the salient determinants to be considered by policy makers for egovernment implementation success are; User participation attributes (UA) and Information and Communication Technology attributes (ICTI). On the contrary, those of Tanzania should that were statistically and positively significant at the time of this study are; top management support (TMS) and user participation attributes (UA). Overall results for combined data from Uganda and that of Tanzania reveal that, user participation attributes (determinants) are paramount and similar in e-government implementation success in both developing countries. Therefore, the governments from both neighbouring East African countries should give relevant support to the e-government users and encourage e-government developers to actively involve end-users in all the phases of e-government development for implementation success.

\section{References}

Abbad, M. M. (2021). Using the UTAUT model to understand students' usage of e-learning systems in developing countries. Education and Information Technologies, 26(6) 1-20.

Ahmad, D., Lutfiani, N., Ahmad, A. D. A. R., Rahardja, U., \& Aini, Q. (2021). Blockchain Technology Immutability Framework Design in E-Government. Jurnal Administrasi Publik: Public Administration Journal, 11(1), 32-41.

A Multi-Group Analysis of Salient Determinants of E-government Implementation Success in Developing Countries. A Study of Uganda and Tanzania

Sumaya M. Kagoya, Gerald Zachary Paga Tinali \& Jamie Caine 
AlAwadhi, S., \& Morris, A. (2008). The use of the UTAUT model in the adoption of egovernment services in Kuwait. 41st Hawaii International Conference on System Sciences, 1-11. UK: Loughborough University.

Alghamdi, I. A., Goodwin, R., \& Rampersad, G. (2016). Ready, set, govern: Readiness of Saudi Arabian organizations for e-government. International Journal of Electronic Government Research (IJEGR), 12(1), 69-98.

Alkraiji, A. I. (2020). An examination of citizen satisfaction with mandatory e-government services: comparison of two information systems success models. Transforming Government: People, Process and Policy, 6(1), 36-58.

Almaiah, M. A., \& Nasereddin, Y. (2020). Factors influencing the adoption of e-government services among Jordanian citizens. Electronic Government, An International Journal, 16(3), 236-259.

Altalhi, M. (2021). Toward a model for acceptance of MOOCs in higher education: the modified UTAUT model for Saudi Arabia. Education and Information Technologies, 26(2), 15891605.

Al-rawahna, A.S., S, Chen, \& Hung, C. (2018). The barriers of e-government success. An empirical study from Jordan. International Journal of Managing Public Sector ICT, 9(2), $1-18$.

Amagoh, F. (2016). Determinants of e-government diffusion in Nigeria: An examination of theoretical models. Information Development, 32(4), 1137-1154.

Assaker, G., Hallak, R., Assaf, A. G., \& Assad, T. (2015). Validating a structural model of destination image, satisfaction, and loyalty across gender and age: Multigroup analysis with PLS-SEM. Tourism Analysis, 20(6), 577-591.

Assefa, S., Rorissa, A., \& Alemneh, D. (2021). Digital readiness assessment of countries in Africa: A case study research. Proceedings of the Association for Information Science and Technology, 58(1), 400-404.

Balzarotti, S. (2021). The emotion regulation questionnaire: factor structure and measurement invariance in an Italian sample of community dwelling adults. Current Psychology, 40(10), 4918-4929.

Buijs, A., \& Jacobs, M. (2021). Avoiding negativity bias: Towards a positive psychology of human-wildlife relationships. Ambio, 50(2), 281-288.

Chu, S. K. W., Reynolds, R. B., Tavares, N. J., Notari, M., \& Lee, C. W. Y. (2021). 21 st century skills development through inquiry-based learning from theory to practice. Springer International Publishing.

Chung, S. C., Marlow, S., Tobias, N., Alogna, A., Alogna, I., You, S. L., \& Pillay, D. (2021). Lessons from countries implementing find, test, trace, isolation and support policies in the rapid response of the COVID-19 pandemic: A systematic review. BMJ Open, 11(7), $\mathrm{e} 047832$.

Çuhadar, Ç. E., Kaarbo, J., Kesgin, B., \& Özkeçeci-Taner, B. (2021). Turkish leaders and their foreign policy decision-making style: A comparative and multi-method perspective. Turkish Studies, 22(1), 1-27.

Gonçalves, H. M. M. (2013). Multi-group invariance in a third-order factorial model: Attribute satisfaction measurement. Journal of Business Research, 66(9), 1292-1297. 
Creswell, C., Shum, A., Pearcey, S., Skripkauskaite, S., Patalay, P., \& Waite, P. (2021). Young people's mental health during the COVID-19 pandemic. The Lancet Child \& Adolescent Health, 5(8), 535-537.

Çuhadar, Ç. E., Kaarbo, J., Kesgin, B., \& Özkeçeci-Taner, B. (2021). Turkish leaders and their foreign policy decision-making style: A comparative and multi-method perspective. Turkish Studies, 22(1), 1-27.

Dewi, C. K., Mohaidin, Z., \& Murshid, M. A. (2019). Determinants of online purchase intention: a PLS-SEM approach: evidence from Indonesia. Journal of Asia Business Studies, 13(4), 281-306.

Dong, L., Neufeld, D., \& Higgins, C. (2009). Top management support of enterprise systems implementations. Journal of Information Technology, 24(1), 55-80.

Eapen, B. (2021). Towards a Theory of Adoption and Design for Clinical Decision Support Systems. PhD thesis, McMaster University, Canada.

Dias, G. P. (2020). Global e-government development: besides the relative wealth of countries, do policies matter? Transforming Government. People, Process and Policy, 6(1), 381400.

Elbahnasawy, N. G. (2021). Can e-government limit the scope of the informal economy? World Development, 139(10), 41-56.

Fan, J., \& Yang, W. (2015). Study on E-Government Services Quality: The Integration of Online and Offline Services. Journal of Industrial Engineering and Management, 8(3), 693-718.

Gerger, A. (2021). Technologies for connected government implementation: Success factors and best Practices. In Web 2.0 and Cloud Technologies for Implementing Connected Government (pp. 36-66). IGI Global.

Ghazali, E. M., Mutum, D. S., \& Javadi, H. H. (2021). The impact of the institutional environment and experience on social entrepreneurship: A multi-group analysis. International Journal of Entrepreneurial Behavior \& Research, 27(9), 15-37.

Glyptis, L., Christofl, M., Vrontis, D., Gildice, M., Mitrious, S., \& Michael, P. (2020). EGovernment implementation challenges in small countries: The project manager's perspective. Technological Forecasting and Social Change, 152(7), 119-135.

Gong, Y., Yang, J., \& Shi, X. (2020). Towards a comprehensive understanding of digital transformation in government: Analysis of flexibility and enterprise architecture. Government Information Quarterly, 37(3), 101-118.

Haydari, S. (2020). Assessing e-government readiness in Iranian universities, case study: Tarbiat Modares University. Journal of Information and Communication Technology, 43(43), 114.

Hair, J. F., Sarstedt, M., Ringle, C. M., \& Gudergan, S. P. (2018). Advanced Issues in Partial Least Squares Structural Equation Modeling (PLS-SEM). CA: Sage.

Halsbenning, S., Niemann, M., Distel, B., \& Becker, J. (2021, March). Playing (Government) seriously: Design principles for e-government simulation game platforms. In International Conference on Wirtschaftsinformatik (pp. 73-90). Springer, Cham

Henseler, J., Ringle, C. M., \& Sinkovics, R. R. (2009). the use of partial least squares path modeling in international marketing. Advances in International Marketing, 20(5), 277320.

Henseler, J., Ringle, C. M., and Sarstedt, M. (2016). Testing measurement invariance of

A Multi-Group Analysis of Salient Determinants of E-government Implementation Success in Developing Countries. A Study of Uganda and Tanzania

Sumaya M. Kagoya, Gerald Zachary Paga Tinali \& Jamie Caine 
composites using partial least squares. International Marketing Review, 33(3), 405-431.

Ingrams, A., Manoharan, A., Schmidthuber, L., \& Holzer, M. (2020). Stages and determinants of e-government development: a twelve-year longitudinal study of global cities. International Public Management Journal, 23(6), 731-769.

Jamal, T., Zahid, M., Martins, J. M., Mata, M. N., Rahman, H. U., \& Mata, P. N. (2021). Perceived green human resource management practices and corporate sustainability: Multigroup analysis and major industries perspectives. Sustainability, 13(6), 30-45.

Joa, C. Y., \& Magsamen-Conrad, K. (2021). Social influence and UTAUT in predicting digital immigrants' technology use. Behaviour \& Information Technology, 40(8), 1-19.

Kabba, J. A., Bah, A. J., James, P. B., Chang, J., Kitchen, C., Jiang, M., \& Fang, Y. (2021). Patients' satisfaction with free healthcare pharmaceutical services in Sierra Leone: A national cross-sectional study. International Journal of Clinical Pharmacy, 43(3), 556565.

Kagoya, M, S., \& Mbamba, U. O. (2020). The influence of user participation attributes in eGovernment implementation success in developing Countries: A study of Uganda. University of Dar es Salaam Library Journal, 15(2), 3-20.

Kagoya, S., \& Mbamba, U. (2021). User participation approach to key attributes of egovernment implementation in developing countries: A case of Tanzania. Business Management Review, 24(1), 87-107.

Kagoya, S. M., \& Mbamba, U. O. (2021). The moderating effect of top management support on key attributes to e-government implementation success in developing countries: A study of Ugandan ministries. ORSEA Journal, 10(2), 33-51.

Kagoya, S. M., \& Gilbert, M. (2020). An E-government readiness assessment framework for Ugandan Ministries. ORSEA Journal, 10(1), 1-20.

Kaaya, J. (2012). Implementing e-Government services in East Africa: Assessing status through content analysis of government Wwbsites. Electronic Journal of e-Government, 2(1), 3954.

Kazdin, A. E. (2021). Research design in clinical psychology. Cambridge University Press.

Keung, C. P., Cheung, A. C., Mak, B. S., \& Tam, W. W. (2021). Perceptions of Hong Kong secondary school teachers on effective pedagogical practices for curriculum reform: A multi-group analysis. Asia Pacific Journal of Education, 41(3) 1-13.

Khan, A., Krishnan, S., \& Dhir, A. (2021). Electronic government and corruption: Systematic literature review, framework, and agenda for future research. Technological Forecasting and Social Change, 167(C), 120-137.

Kock, F., Berbekova, A., \& Assaf, A. G. (2021). Understanding and managing the threat of common method bias: Detection, prevention and control. Tourism Management, 86(10); 43-59.

Kuppelwieser, V. G., \& Klaus, P. (2021). Measuring customer experience quality: The EXQ scale revisited. Journal of Business Research, 126(Issue C) 624-633.

Kurfalı, M., Arifoğlu, A., Tokdemir, G., \& Paçin, Y. (2017). Adoption of e-government services in Turkey. Computers in Human Behavior, 66(10), 168-178.

Low, M. P., Cham, T. H., Chang, Y. S., \& Lim, X. J. (2021). Advancing on weighted PLS-SEM in examining the trust-based recommendation system in pioneering product promotion effectiveness. Quality \& Quantity, 2021(5),1-30. 
Li, W. (2021). The Role of Trust and Risk in Citizens' E-Government Services Adoption: A perspective of the extended UTAUT model. Sustainability, 13(14), 71-86.

Li, W., \& Xue, L. (2021). Analyzing the critical factors influencing post-use trust and its impact on citizens' continuous-use intention of e-government: Evidence from Chinese municipalities. Sustainability, 13(14), 7698.

Malodia, S., Dhir, A., Mishra, M., \& Bhatti, Z. A. (2021). Future of e-Government: An integrated conceptual framework. Technological Forecasting and Social Change, 173( C), 121-136.

Manoharan, A. P., Ingrams, A., Kang, D., \& Zhao, H. (2021). Globalization and worldwide best practices in e-Government. International Journal of Public Administration, 44(6), 465476.

Magayane, A. A., Mokua, J. K., \& Lanrong, Y. (2016). Evaluation of the current status of egovernment implementation in Tanzania: Government websites perspectives. ACSIJ Advances in Computer Science, 5(2), 47-55.

Maznorbalia, A. S., \& Awalluddin, M. A. (2021). Users acceptance of e-government system in Sintok, Malaysia: Applying the UTAUT Model. Policy \& Governance Review, 5(1), 6681.

Moon J. (2002). The evolution of e-government among municipalities: rhetoric or reality? Public Administation Review 62(4), 424-433.

Mücke, M., Cuhls, H., Radbruch, L., Baron, R., Maier, C., Tölle, T., \& Rolke, R. (2021). Quantitative sensory testing (QST). English version. Der Schmerz, 35(3), 153-160.

Ngah, A. H., Gabarre, S., Han, H., Rahi, S., Al-Gasawneh, J. A., \& Park, S. H. (2021). Intention to purchase halal cosmetics: do males and females differ? A multigroup analysis. Cosmetics, 8(1), 19-36.

Olugbara, O. O., \& Joseph, S. (2018). Evaluation of municipal e-government readiness using structural equation modelling technique. TD: The Journal for Transdisciplinary Research in Southern Africa, 14(1), 1-10.

Olya, H., Taheri, B., Farmaki, A., \& Joseph Gannon, M. (2021). Modelling perceived service quality and turnover intentions in gender-segregated environments. International Journal of Consumer Studies, 33(2), 1-17.

Pal, A., Singh, D., \& Dhaliwal, R. K. (2020). Identification and relevance of e-readiness assessment tools for ICT use in agriculture. Current Journal of Applied Science and Technology, 39(16), 93-102.

Perucchetti, L., Bray, P., Felicetti, A., Sainsbury, V., Howarth, P., Saunders, M. K., \& Pollard, M. (2021). FLAME-D database: An integrated system for the Study of archaeometallurgy. Archaeometry, 63(3), 651-667.

Poerwandari, E. K. (2021). Minimizing bias and maximizing the potential strengths of autoethnography as a narrative research. Japanese Psychological Research, 63(4), 213229.

Pontes, H. M., Schivinski, B., Sindermann, C., Li, M., Becker, B., Zhou, M., \& Montag, C. (2021). Measurement and conceptualization of gaming disorder according to the World health organization framework: The development of the gaming disorder test. International Journal of Mental Health and Addiction, 19(2), 508-528.

A Multi-Group Analysis of Salient Determinants of E-government Implementation Success in Developing Countries. A Study of Uganda and Tanzania

Sumaya M. Kagoya, Gerald Zachary Paga Tinali \& Jamie Caine 
Qaid, E. H., Samikon, S. A., \& Al Fahmi, N. (2021). Factors Influencing the adoption of egovernment among University's lectures in Yemen. Journal of Internet Banking and Commerce, 26(1), 1-12.

Raza, S. A., Qazi, W., Khan, K. A., \& Salam, J. (2021). social isolation and acceptance of the learning management system (LMS) in the time of COVID-19 Pandemic: An expansion of the UTAUT model. Journal of Educational Computing Research, 59(2), 183-208.

Ragu-Nathan, B. S., Apigian, C. H., Ragu-Nathan, T. S., \& Tu, Q. (2004). A path analytic study of the effect of top management support for information systems performance. Omega, 32(6), 459-471.

Rehman Khan, S. A., \& Yu, Z. (2021). Assessing the eco-environmental performance: An PLSSEM approach with practice-based view. International Journal of Logistics Research and Applications, 24(3), 303-321.

Ritchie, B. W., Sie, L., Gössling, S., \& Dwyer, L. (2020). Effects of climate change policies on aviation carbon offsetting: A three-year panel study. Journal of Sustainable Tourism, 28(2), 337-360.

Roblek, V., Bach, M. P., Meško, M., \& Bertoncel, T. (2020). Best practices of the social innovations in the framework of the e-government evolution. Amfiteatru Economic, 22(53), 275-302.

Rodrigues, G., Sarabdeen, J., \& Balasubramanian, S. (2016). Factors that influence consumer adoption of e-government services in the UAE: A UTAUT model perspective. Journal of Internet Commerce, 15(1), 18-39.

Sarstedt, M., Henseler, J., \& Ringle, C. M. (2011). Multi-group analysis in partial least squares (pls) path modeling: Alternative methods and empirical results, Advances in International Marketing, 22(4), 195-218.

Salehi, F., Abdollahbeigi, B., \& Sajjady, S. (2021). IT governance maturity and its impact on Organizational performance. Asian Journal of Economics, Finance and Management, $3(2), 46-50$.

Saunders, C. A. (2021). The Effects of Leadership Styles on Employee Turnover: A Quantitative Analysis. PhD Thesis, Northcentral University, California, USA.

Schreurs, L., \& Vandenbosch, L. (2021). The development and validation of measurement instruments to address interactions with positive social media content. Media Psychology, 24(6), 1-28.

Shareef, M. A., Kumar, V., Kumar, U., \& Dwivedi, Y. K. (2011). E-Government adoption model (GAM): Differing service maturity levels. Government information quarterly, 28(1), 17 35

Sharma, S. K., Metri, B., Dwivedi, Y. K., \& Rana, N. P. (2021). Challenges common service centers (CSCs) face in delivering e-government services in rural India. Government Information Quarterly, 38(2), 101-115.

Singh, H., Grover, P., Kar, A. K., \& Ilavarasan, P. V. (2020). Review of performance assessment frameworks of e-government projects. Transforming Government: People, Process and Policy, 14(1), 31-64.

Toyoda, R., Russo Abegão, F., Gill, S., \& Glassey, J. (2021). Drivers of immersive virtual reality adoption intention: a multi-group analysis in chemical industry settings. Virtual Reality, 25(4) 1-12. 
Tsang, V. W. L., Papamihali, K., Crabtree, A., \& Buxton, J. A. (2021). Acceptability of technological solutions for overdose monitoring: Perspectives of people who use drugs. Substance Abuse, 42(3), 284-293.

Uyar, A., Nimer, K., Kuzey, C., Shahbaz, M., \& Schneider, F. (2021). Can e-government initiatives alleviate tax evasion? The moderation effect of ICT. Technological Forecasting and Social Change, 166 (12), 59-77.

Venkatesh, V. (2021). Adoption and use of AI tools: a research agenda grounded in UTAUT. Annals of Operations Research, 307(12); 1-12.

Verkijika, S. F., \& De Wet, L. (2018). A usability assessment of e-government websites in SubSaharan Africa. International Journal of Information Management, 39(8) 20-29.

Vo, L. N. Q., Codlin, A., Ngo, T. D., Dao, T. P., Dong, T. T. T., Mo, H. T. L., \& Creswell, J. (2021). Early evaluation of an ultra-portable x-ray system for tuberculosis active case finding. Tropical Medicine and Infectious Disease, 6(3), 163-179.

Walker, D., Parkin, G., Schmitter, P., Gowing, J., Tilahun, S. A., Haile, A. T., \& Yimam, A. Y. (2019). Insights from a multi-method recharge estimation comparison study. Groundwater, 57(2), 245-258.

Williamson, V., Larkin, M., Reardon, T., Pearcey, S., Hill, C., Stallard, P., \& Creswell, C. (2021). Codesign and development of a primary school-based pathway for child anxiety screening and intervention delivery: a protocol, mixed-methods feasibility study. $B M J$ Open, 11(4), e044852.

Yera, A., Arbelaitz, O., Jauregui, O., \& Muguerza, J. (2020). Characterization of e-Government adoption in Europe. Plos One, 15(4), e0231585.

Zina, O. (2021). The essential guide to doing your research project. Sage.

A Multi-Group Analysis of Salient Determinants of E-government Implementation Success in Developing Countries. A Study of Uganda and Tanzania

Sumaya M. Kagoya, Gerald Zachary Paga Tinali \& Jamie Caine 